\title{
Neurotoxicity of CSF from HIV-infected humans
}

\author{
Rick B Meeker ${ }^{*, 1}$, Kevin Robertson ${ }^{1}$, Tammy Barry ${ }^{1}$ and Colin Hall ${ }^{1}$ \\ ${ }^{1}$ Department of Neurology, University of North Carolina, Chapel Hill, North Carolina, NC 27599, USA
}

\begin{abstract}
Approximately 15-20\% of individuals infected with the human immunodeficiency virus will develop severe neurological disease. This may be due in part to virus-induced release of a number of putative neurotoxins. However, there is little information to predict which individuals will progress to dementia or the precise mechanisms that drive pathogenesis. In an effort to identify early markers of neurological disease progression we used an in vitro bioassay with rat cortical neurons to test for the presence of toxins in CSF from $40 \mathrm{HIV}$ infected humans with mild, minimal or no neurological disease. A subset of HIV-infected individuals was found to have significant toxic activity in CSF indicating that toxic factors may be circulating prior to the development of dementia. The toxicity was concentration dependent and due to a factor with a molecular mass of less than $30 \mathrm{kDa}$. Only a small proportion of the cell death appeared to be due to apoptosis. Neuronal toxicity was associated with a gradual accumulation of intracellular calcium in a subset of cortical neurons over a period of $1-2 \mathrm{~h}$ and in the absence of a significant acute response. Individuals with both high viral burden and high CSF toxicity were significantly more likely to have neurological symptoms. These initial analyses indicate that toxic factors are present in the CSF of HIV-infected patients that could serve as useful markers of neurological disease progression and provide insights into pathogenic mechanisms in vivo.
\end{abstract}

Keywords: AIDS; brain; tissue culture; excitotoxicity

\section{Introduction}

The development of neurological disease in individuals infected with human immunodeficiency virus (HIV) is the culmination of a long history of viral interactions with the brain which slowly kill selected cortical and subcortical neurons (Wiley et al, 1991; Ketzler et al, 1990; Weis et al, 1993; Gray et al, 1991). Data from both human and animal studies suggest that the neural disease, is progressive and that it may begin in the asymptomatic stage, long before the development of AIDS (Lendhardt et al, 1988; Elovaara et al, 1990; Meeker et al, 1997). Exposure of the brain to virus appears to be a necessary but not sufficient condition for the development of brain disease, since HIV rapidly penetrates the brain of most individuals but results in severe neurological disease in only a small subset of infected individuals. Efforts to understand the specific viral interactions with the brain that lead to significant neurological disease have focused on the impact of viral burden and the secretion of

*Correspondence: R Meeker

Received 25 January 1999; revised 3 May 1999; accepted 12 July 1999 potentially cytotoxic molecules by microglia/macrophages and astrocytes (Epstein et al, 1997). Plasma viral load has been correlated with systemic disease progression. Recent studies have also suggested a correlation between CSF viral load and neurological disease. Viral RNA titers in CSF from individuals at various stages of disease have correlated with neurological disease status in some studies (McArthur et al, 1997; Robertson et al, 1998; Ellis et al, 1997; Brew et al, 1997) but not others (Bossi et al, 1998; Conrad et al, 1995). However, the significant correlations were only found in individuals with encephalitis or neurocognitive impairment. No predictive value has been found at earlier disease stages. Consequently, the precise role of the virus in the development of brain disease is not clear. Alternative variables that are more closely related to the neurotoxic event might provide better early markers of neuropathogenesis leading to AIDS dementia.

Since HIV does not appear to directly infect and kill neurons, the development of neurological disease probably depends in part on interactions of HIV with microglia/macrophages and astrocytes in the brain. In vitro studies have identified many potential neurotoxic factors of microglia/macro- 
phage origin which could be toxic to neurons (Lipton, 1992a; Giulian et al, 1996; Heyes et al, 1991a,b; Dawson et al, 1993). These in vitro observations are consistent with the correlation between microglial densities in brains of HIVinfected individuals and the development of dementia (Glass et al, 1995). In addition, early activation of microglia in the brain of HIV-infected individuals could provide the opportunity for early toxin production and the initiation of gradual neurodegenerative changes. The leading candidates for soluble neurotoxic factors include viral proteins (gp120, tat) (New et al, 1997; Dreyer et al, 1990; Lipton et al, 1991; Epstein et al, 1997; Nath and Geiger, 1998), quinolinate (Heyes et al, 1991a,b), platlet activating factor (PAF) (Gelbard et al, 1994a), tumor necrosis factor- $\alpha(\mathrm{TNF}-\alpha)$ (Gelbard et al, 1994b), interleukins (Yeung et al, 1995; Holliday et al, 1995), nitric oxide (Dawson et al, 1993; Adamson et al, 1996) and NTox (Giulian et al, 1996). Many of these factors are elevated in the CSF of HIV-infected individuals and could potentially diffuse through the brain to promote the widespread changes seen in HIV encephalitis. Thus the accumulation of toxins in the CSF may at least partially parallel toxic activity within the brain parenchyma. However, little has been done to evaluate whether substances in the CSF of some $\mathrm{HIV}$-infected individuals are cytotoxic at endogenous concentrations and whether this cytotoxic activity might parallel the development of neurological disease. Measures of cytotoxic activity in the CSF of HIV infected individuals could provide significant diagnostic and mechanistic insights into evolving pathogenesis. To test this possibility, we used a cytotoxicity assay in primary cultures of rat cortex to characterize CSF from $\operatorname{HIV}(+)$ and $\operatorname{HIV}(-)$ patients. A subset of $\mathrm{HIV}(+)$ patients was found to have significant cytotoxic activity in CSF at various stages of disease suggesting that the assay may provide a useful index of evolving CNS pathogenesis.

\section{Results}

\section{Effects of HIV(+) CSF on cell death and LDH accumulation in cortical cultures}

A total of 54 human CSF samples [40 HIV(+) and 14 $\mathrm{HIV}(-)]$ were screened for toxic activity using rat cortical cultures as a test system. All CSF samples were cell-free and filtered through an ultrafiltration membrane with a 30000 Da cutoff to provide a virus-free preparation. $\mathrm{HIV}(+)$ patients represented a wide range of disease based on 1993 CDC criteria including nine at stage 0 , seven at stage 1,18 at stage 2 and six patients with no HIV-associated disease. Mild to moderate neurological disease was seen in two patients, minimal neurological symptoms in nine and no neurological symptoms in 29 patients.
Initial cytotoxicity screening studies using a 1:5 dilution of CSF in the culture medium indicated that $\mathrm{HIV}(+) \mathrm{CSF}$ from a subset of patients induced cell death in vitro. One $\operatorname{HIV}(-)$ CSF sample also showed a small level of cytotoxic activity relative to aCSF internal controls. To evaluate the relative potency of the $\operatorname{HIV}(+)$ and the $\operatorname{HIV}(-)$ CSF, a concentration-effect curve for cell death (ethidium homodimer stain) was run on CSF samples using the most cytotoxic HIV(-) CSF as well as HIV(+) CSF with high, medium and low levels of cytotoxic activity based on the initial screen. The results of this analysis, summarized in Figure 1, illustrate that the HIV(+) CSF was more potent than the $\operatorname{HIV}(-)$ CSF with peak cytotoxic activity achieved at a dilution of $1: 10-1: 30$. The most toxic HIV $(-)$ CSF sample, on the other hand $(\operatorname{HIV}(-) \mathrm{c})$, began showing signs of activity at a dilution of $1: 5-$ $1: 10$. Repeated HIV(+) samples run at CSF dilutions of $1: 10-1: 30$ had an average of $67.7 \pm 11.4$ (s.e.m.) dead cells $/ \mathrm{mm}^{2}$ relative to $23.9 \pm 7.0$ dead cells/ $\mathrm{mm}^{2}$ for the $\mathrm{HIV}(-)$ CSF indicating an average within sample variability of $16.8 \%$ and $29.0 \%$, respectively. Given these values a change of $\pm 57 \%$ can conservatively be detected. All subsequent tests were run at dilutions of $1: 20$ to maximize the separation between the $\operatorname{HIV}(+)$ and $\mathrm{HIV}(-)$ CSF. Under these conditions, basal cell death in cultures treated with the internal non-toxic aCSF control averaged $37.7 \pm 9.4 \mathrm{cells} / \mathrm{mm}^{2}$. This value represents approximately $2.5 \%$ of the total neuronal population. A summary of the cytotoxic activity of

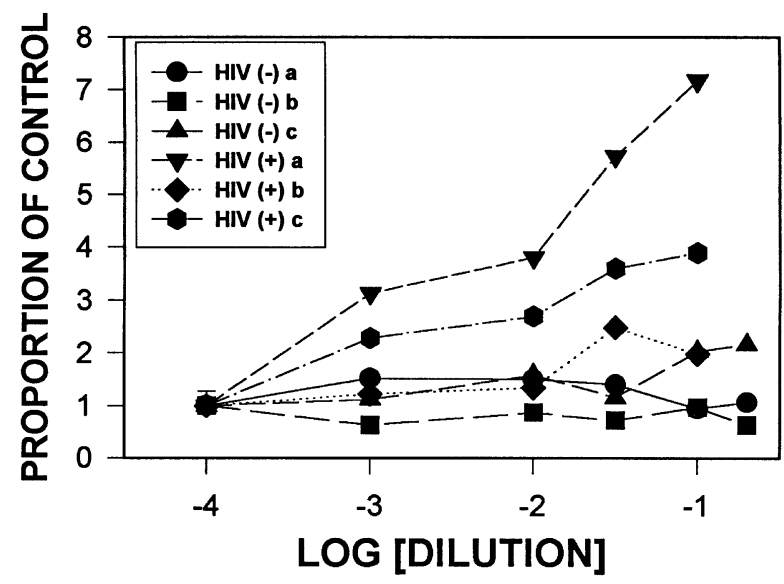

Figure 1 Proportional increase in cell death based on ethidium homodimer staining relative to artificial CSF controls for CSF samples collected from three HIV-infected $(+)$ individuals (HIV(+)a,b,c) or three uninfected (HIV $(-)$ a,b,c) individuals. HIV-infected CSF samples were chosen from those that gave reliable increases in toxicity in initial screening assays. These HIV(+) samples showed high, medium and low levels of toxic activity but were always greater than respective controls. Toxicity began to appear at a CSF dilution of $1: 1000$ in the most active sample. One control sample showed a significant toxic activity at a dilution of $1: 10-1: 5$. All tests were run in dissociated cortical cultures. 
all CSF samples relative to basal cell death is provided in Figure 2. Addition of a 1:20 dilution of $\mathrm{HIV}(+) \mathrm{CSF}$ into the medium of rat cortical cultures resulted in a wide range of cytotoxic activity. HIV $(-)$ CSF fell within a much narrower range of values with a mean increase in cell death of $55.0 \pm 9.5 \%$. To define significant elevations in cytotoxic activity within the population of $\operatorname{HIV}(+)$ CSF samples, a 95\% confidence limit was calculated from the $\mathrm{HIV}(-)$ samples (mean \pm 1.96 s.d. units). The cutoff value is illustrated by a horizontal line at $92.2 \%$. A subset of HIV(+) CSF $(13 / 40$ or $32.5 \%$ ) showed cytotoxic activity in the CSF beyond the $95 \%$ confidence limit. No HIV(-) CSF sample was significant.

A parallel analysis of lactate dehydrogenase (LDH) activity in the medium on the day after addition of the CSF, resulted in a similar but less sensitive profile of cytotoxicity (Figure 3 ). Cultures treated with $\mathrm{HIV}(-)$ CSF showed a negligible average net increase in LDH activity of $0.0027 \pm 0.0014 \mathrm{units} / \mathrm{ml}$ (Uml). Using a 95\% confidence limit calculated from the HIV $(-)$ results, a total of $5 / 40 \mathrm{HIV}(+)$ CSF samples $(12.5 \%)$ showed significant cytotoxic activity. Within the HIV(+) group, CSF-treated cultures showing significant cell death by ethidium homodimer staining also had a large mean increase in LDH activity of $11.68 \pm 4.02 \%$ relative to an increase of $0.43 \pm 2.04 \%$ for CSF-treated cultures that did not have significant cell death. A few HIV(+) CSF samples were less cytotoxic or produced less LDH activity than the control HIV $(-)$ CSF. However, these were in the range of values seen with application of artificial CSF $(-5.1 \pm 4.2 \quad[n=40]$ relative to $\mathrm{HIV}(-) \mathrm{CSF})$.
The ability to detect LDH activity in cultures treated with CSF, provided the opportunity to examine the temporal characteristics of the cytotoxicity. The accumulation of LDH activity at 1, 4, 12 and $24 \mathrm{~h}$ within the same cultures after addition of toxic $\mathrm{HIV}(+) \mathrm{CSF}$ is illustrated in Figure 4. HIV(+) CSF induced a rise in LDH activity within the first $2 \mathrm{~h}$ which continued to increase slowly over the following $22 \mathrm{~h}$. A gradual rise in $\mathrm{LDH}$ activity was seen in the HIV $(-)$, and control (aCSF) groups. The control groups did not differ from one another. $\mathrm{LDH}$ activity was significantly increased in the $\mathrm{HIV}(+)$ CSF group at 1 and $24 \mathrm{~h}$. An additional experiment was done to evaluate the accumulation of $\mathrm{LDH}$ activity in cultures treated with HIV(+) CSF in the absence of $\mathrm{Mg}^{2+}$, a condition that enhances activity at the NMDA glutamate receptor. Both HIV(+) groups showed significantly higher LDH activity than the $\mathrm{HIV}(-)$ control. Culturing in $\mathrm{Mg}^{2+}$-free medium produced a modest additional increase in the mean LDH accumulation relative to $\mathrm{HIV}(+) \mathrm{CSF}$ in the absence of $\mathrm{Mg}^{2+}$ (Figure 5).

\section{$L D H$ activity in $C S F$ in vivo}

To rule out the possibility that LDH in CSF might have contributed to the LDH activity in the cultures and to test the possibility that $\mathrm{LDH}$ activity in CSF might provide a useful marker for in vivo cytotoxic activity, we measured the LDH activity in undiluted CSF from all fresh CSF samples $(n=31)$. A low level of $\mathrm{LDH}$ activity could be measured from most CSF samples. However, no significant differences were seen between the $\mathrm{HIV}(+)$ and the $\mathrm{HIV}(-)$ CSF. In addition, the mean total LDH activity of $0.0110 \mathrm{U} / \mathrm{ml}$ in raw CSF was too low to account for any of the $\mathrm{LDH}$

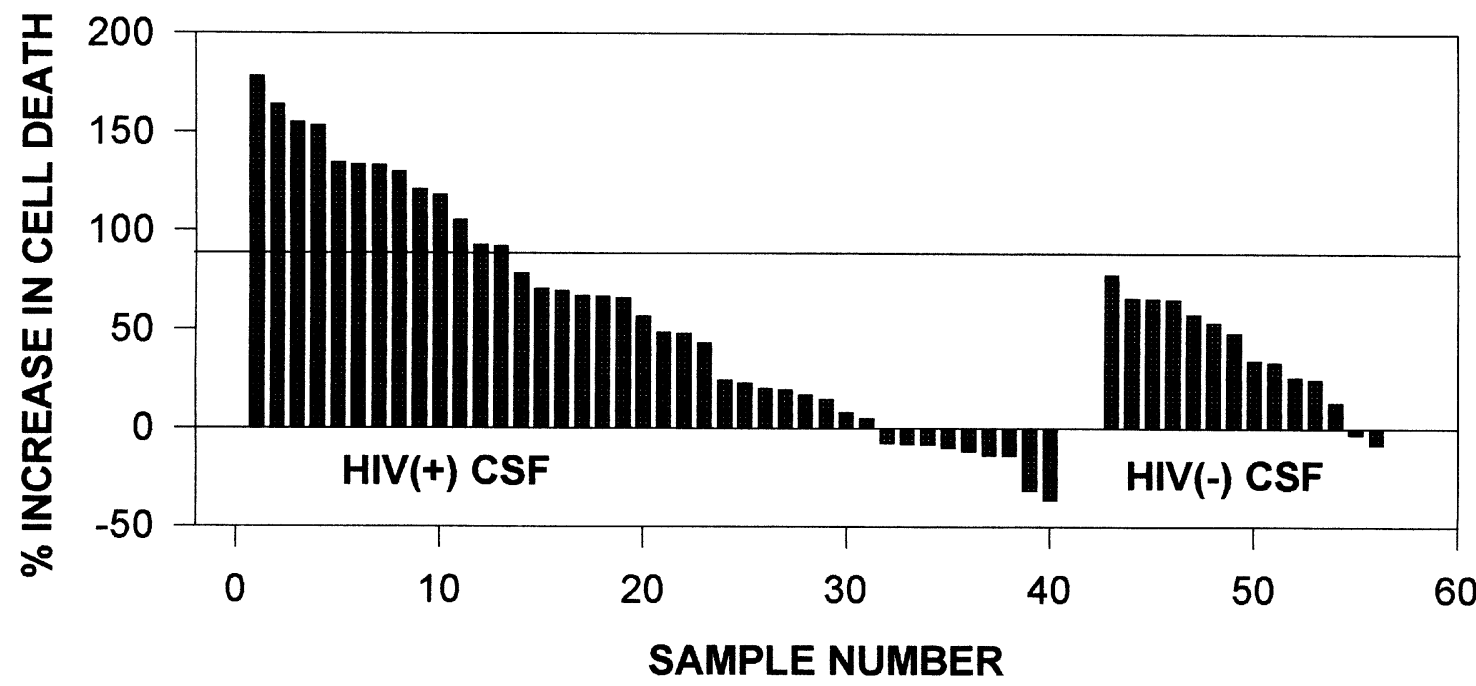

Figure 2 Toxicity profile of all HIV(+) and HIV(-) CSF samples. A subset of HIV(+) CSF showed a level of ethidium homodimer staining significantly greater than the $\mathrm{HIV}(-)$ controls based on the $95 \%$ confidence limit of the controls illustrated by the horizontal line (mean+1.96 s.d.). All CSF samples were tested on dissociated rat cortical cultures at a dilution of $1: 20$ for $28 \mathrm{~h}$. 
activity seen in the cultures (mean $=0.0401 \mathrm{U} / \mathrm{ml}$ ) where the CSF is diluted 20-fold.

The active toxins have a molecular mass of less than $30 \mathrm{kDa}$

Since ultrafiltration of the CSF through a 30000 molecular weight cutoff filter could have removed viral particles and large proteins with significant toxic activity, we directly compared the activity of ultrafiltered CSF to raw unfiltered CSF. Ten HIV(+) CSF samples were chosen that reflected the entire range of toxic activities. As illustrated in pairwise comparisons in Figure 6, all of the toxic activity could be accounted for by the $30 \mathrm{kDa}$ ultrafiltrate.

\section{Apoptosis versus necrosis}

The cell death triggered by exposure to HIV(+) CSF could be due to necrotic or apoptotic

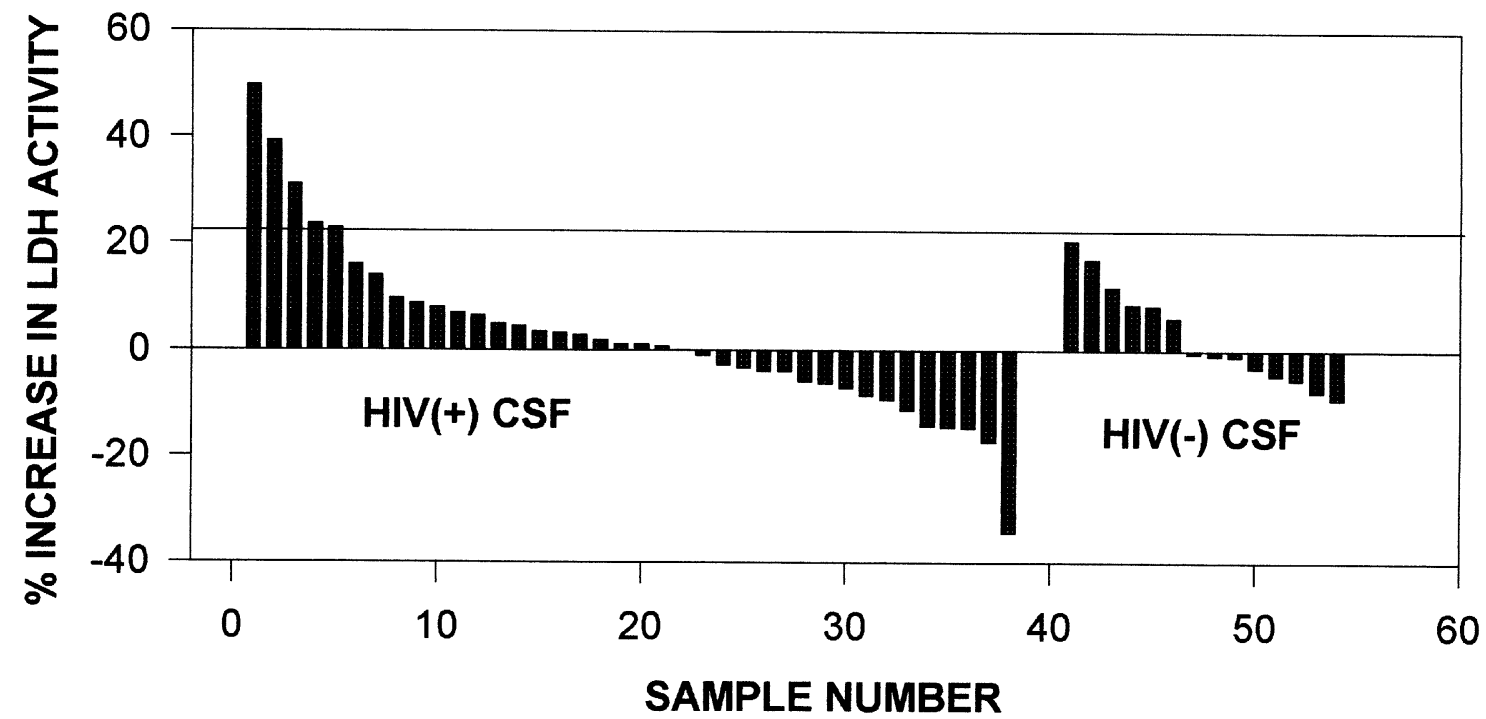

Figure 3 Toxicity profile of all HIV(+) and HIV(-) CSF samples. A subset of HIV(+) CSF showed a level of LDH accumulation significantly greater than the $\mathrm{HIV}(-)$ controls based on the $95 \%$ confidence limit of the controls illustrated by the horizontal line (mean+1.96 s.d.). All CSF samples were tested on dissociated rat cortical cultures at a dilution of $1: 20$ for $28 \mathrm{~h}$.

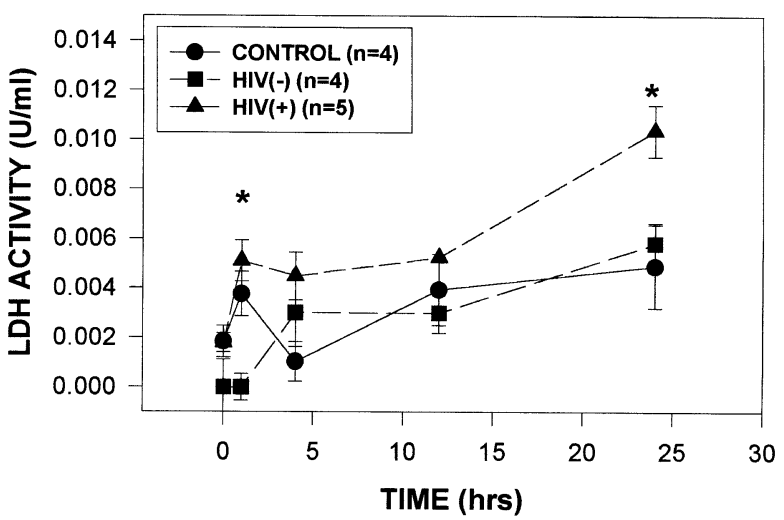

Figure 4 Time course of LDH accumulation after exposure to HIV(+) human CSF previously shown to have high levels of toxicity, HIV $(-)$ CSF or artificial CSF controls. LDH activity in dissociated cortical cultures increased quickly (by $1 \mathrm{~h}$ ) after exposure to toxic CSF. Controls and $\mathrm{HIV}(-) \mathrm{CSF}$ showed a gradual accumulation of LDH activity over time that was consistently lower than the toxic CSF. All CSF was run at a dilution of $1: 20$. ${ }^{*} P<0.02$.

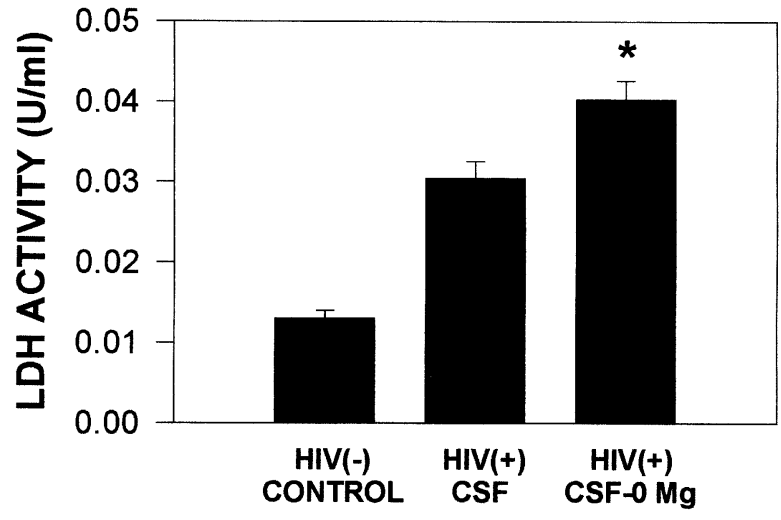

Figure 5 Enhanced accumulation of LDH activity in dissociated cortical cultures treated with toxic $\mathrm{HIV}(+) \mathrm{CSF}$ in magnesiumfree $(0 \mathrm{Mg})$ medium. The accumulation of $\mathrm{LDH}$ activity (absorbance units/min) seen with toxic $\operatorname{HIV}(+) \operatorname{CSF}(n=7)$ was further increased in the absence of magnesium $\left({ }^{*} t=-3.32\right.$, $P=0.006, n=7$ each group). CSF was assayed at a dilution of $1: 20$ for $24 \mathrm{~h}$ in culture. Both HIV(+) CSF conditions produced significantly more LDH activity than the $\mathrm{HIV}(-)$ controls $(P<0.007)$. Basal LDH accumulation under the same conditions was $0.0053 \pm .0004$ absorbance units $/ \mathrm{min}$. Bars represent the mean \pm s.e.m. 
mechanisms. To contrast the contribution of these two processes, cultures were incubated overnight with toxic $\mathrm{HIV}(+) \mathrm{CSF}$ or $\mathrm{HIV}(-)$ CSF. After treatment, dead cells were labeled with ethidium homodimer and counted. The cells were then fixed and the fragmented DNA was end-labeled with biotinylated deoxynucleotides using terminal deoxynucleotidyl transferase (TUNEL proce-

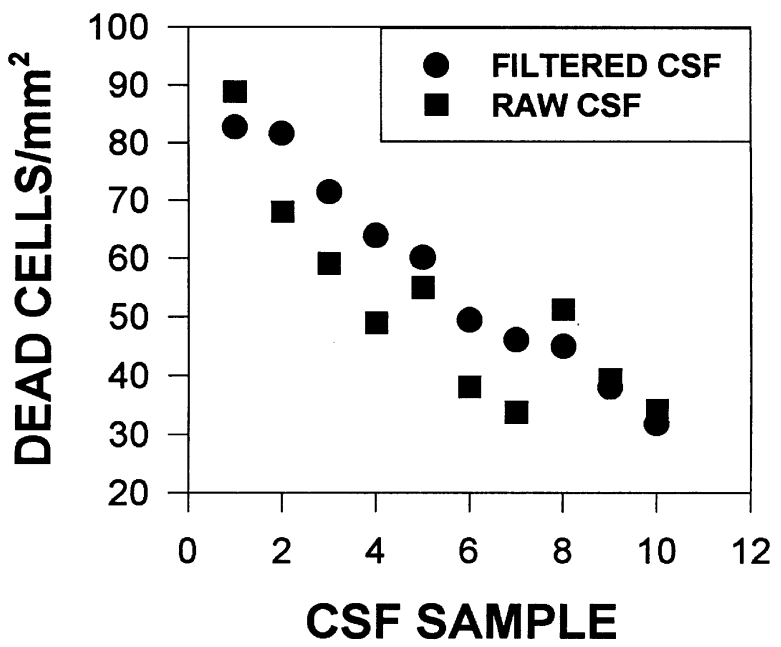

Figure 6 Comparison of the toxic activity (dead cells $/ \mathrm{mm}^{2}$ ) of 10 raw and ultrafiltered CSF samples representing the full range of toxic activities. Pairwise comparisons of cell death in dissociated cortical cultures due to raw CSF versus an ultrafiltrate (30000 molecular weight cutoff) of the same sample indicated that all of the toxic activity in each sample could be accounted for by the low molecular weight components in the ultrafiltrate. dure). An average of $37.4 \pm 8.6(n=5)$ apoptotic cells were seen in cultures treated with HIV $(-)$ CSF relative to $30.4 \pm 6.4 \quad(n=9)$ for cultures treated with HIV(+) CSF. Corresponding ethidium staining of dead cells gave values of $56.6 \pm 10.7$ and $75.6 \pm 12.8$ for $\mathrm{HIV}(-)$ and $\operatorname{HIV}(+) \mathrm{CSF}$, respectively. Basal cell death was $47.0 \pm 6.9$ in this assay. In cultures with the highest level of cell death $(104.5 \pm 14.7$; $\mathrm{HIV}(+) \mathrm{CSF}, n=5)$, the corresponding apoptosis was only $24.7 \pm 9.3$ indicating that as more cells die, the ratio of apoptotic to dead cells decreases.

\section{Intracellular calcium accumulation in neurons}

Since accumulation of intracellular $\mathrm{Ca}^{2+}$ plays a crucial role in triggering excitotoxic cell death, we evaluated the ability of $\mathrm{HIV}(+) \mathrm{CSF}$ to disrupt $\mathrm{Ca}^{2+}$ homeostasis in the cortical neurons. The mean calcium accumulations within rat cortical neurons treated with $\operatorname{HIV}(+) \operatorname{CSF}(n=18), \operatorname{HIV}(-)$ CSF $(n=18)$ and aCSF $(n=7)$ are summarized in Figure 7. Addition of $\mathrm{HIV}(+) \mathrm{CSF}$ to neurons preloaded with the $\mathrm{Ca}^{2+}$ indicator dye Fluo-3 induced two very small acute increases in intracellular $\mathrm{Ca}^{2+}$ at 12 and $60 \mathrm{~s}$ post-stimulation followed by recovery to basal levels by 2 min. Between 10 and 30 min after the addition of the CSF, intracellular $\mathrm{Ca}^{2+}$ again began to rise and, by $1 \mathrm{~h}$, reached a level more than tenfold greater than the initial acute peak responses. Neither the $\operatorname{HIV}(-)$ CSF or the aCSF induced a change in intracellular $\mathrm{Ca}^{2+}$ within the first $60 \mathrm{~min}$. Of the 18 neurons tested in three experiments with HIV(+) CSF, 13 showed fluorescence increases in excess of $50 \%$ over basal and 11/18 showed increases in excess of $100 \%$. None of the neurons tested with $\operatorname{HIV}(-)$
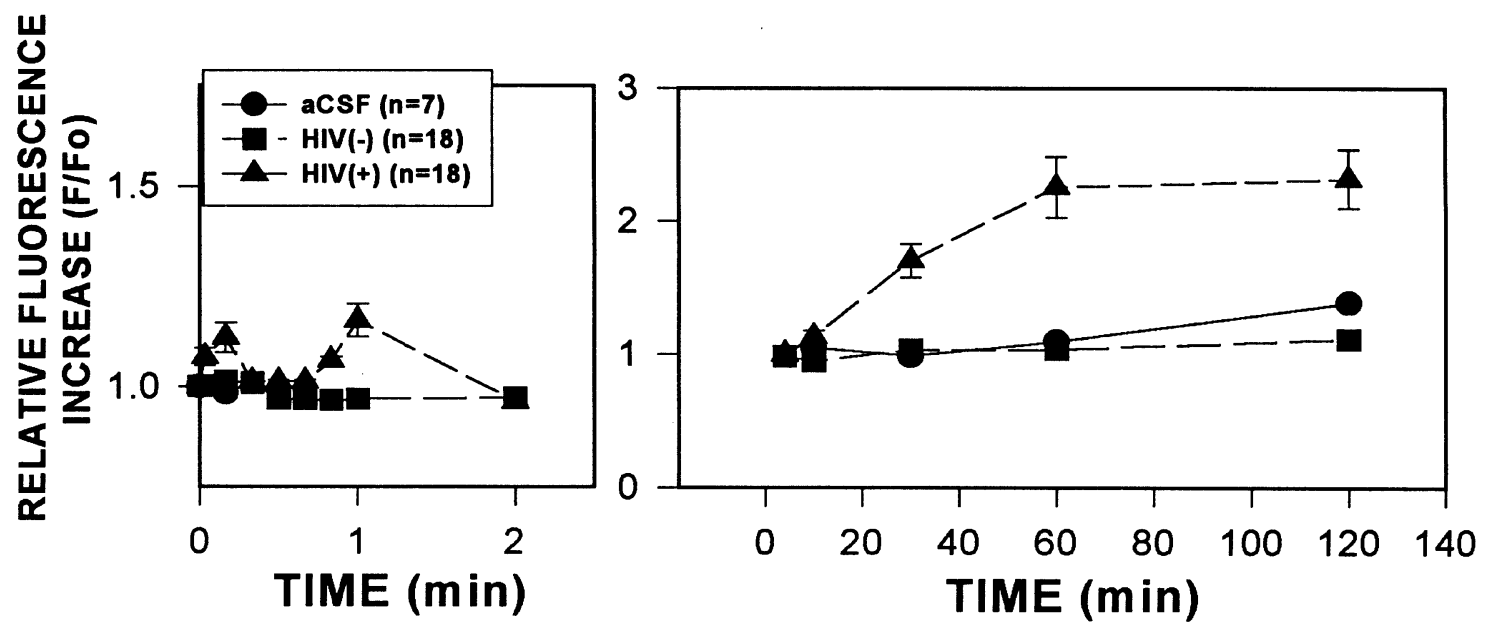

Figure 7 Mean increase in intracellular calcium in neurons from rat cortical punches treated with a $1: 20$ dilution of HIV(+) CSF. The HIV(+) CSF was selected from a sample previously shown to have toxic activity in the ethidium homodimer assay. Cells were preloaded with the fluorescent calcium indicator dye Fluo-3 AM 40 min prior to testing. Very small peaks of calcium fluorescence were seen due to the $\mathrm{HIV}(+) \mathrm{CSF}(n=18$ cells) at $10 \mathrm{~s}(P=0.289)$ and $60 \mathrm{~s}(P=0.0001)$ which recover to baseline by 2 min. All time points $30 \mathrm{~min}$ and beyond are significantly greater than the HIV $(-)$ CSF controls $(P<0.0001)$. 
CSF (0/18) or aCSF (0/7) showed fluorescence increases in excess of $50 \%$ over basal. An example of the $\mathrm{Ca}^{2+}$ accumulation in a small cluster of cortical neurons treated with $\mathrm{HIV}(+)$ or $\mathrm{HIV}(-) \mathrm{CSF}$ is illustrated in Figure 8. Of the five neurons treated with the $\mathrm{HIV}(+) \mathrm{CSF}$, four showed small acute increases. One large neuron (arrow) showed a dramatic gradual accumulation of intracellular $\mathrm{Ca}^{2+}$ culminating in extreme swelling and death by $120 \mathrm{~min}$. No such responses have been observed in similar neurons exposed to HIV(-) CSF (open arrow, arrowhead) which show only a small accumulation of $\mathrm{Ca}^{2+}$ beginning at $60 \mathrm{~min}$.

\section{Relationship of CSF toxicity to viral load and clinical status}

Although comparisons of clinical data with in vitro toxicity must be interpreted cautiously in the absence of longitudinal data, several trends are notable. The patients with toxic CSF (Tox $(+))$ were equally divided between asymptomatic, symptomatic and AIDS ( $n=4$ each) suggesting that toxic factors appear in the CSF at all disease stages. The Tox $(-)$ group had 13 AIDS patients, five asymptomatic and three symptomatic. The relative toxicity of the CSF did not correlate with the development of immunodeficiency. AIDS patients had an average toxicity score (per cent increase in cell death) of $130.8 \pm 14.8$ versus $140.1 \pm 8.7$ in asymptomatic patients. Correlation of the relative toxicity of CSF, plasma viral RNA and CSF viral RNA with a dichotomous ranking of neurological function (normal-stage 0 versus stage $0.5-1$ based on Price and Sidtis (1990) is summarized in Table 1 . No significant positive relationships were seen for any of these variables. However, using an additive model to assess the potential combined contributions of viral burden and toxic factors substantially increased the correlation. A combination of high CSF toxicity and high viral burden was the best predictor of neurological disease $(r=0.559)$. The combined relationship of plasma virus with CSF toxicity showed a significant but weaker correlation.

Table 1 Relationship between CSF toxicity, viral burden and neurological status.

\begin{tabular}{lcc}
\hline & Correlation & Probability \\
\hline Plasma viral RNA & 0.241 & $P=0.128$ \\
CSF viral RNA & 0.270 & $P=0.093$ \\
CSF Toxicity & -0.145 & $P=0.345$ \\
Toxicity+Plasma viral RNA & 0.340 & $P=0.034$ \\
Toxicity+CSF viral RNA & 0.559 & $P=0.0002$ \\
\hline
\end{tabular}

The correlation of CSF toxicity (\% increase in cell death), CSF viral RNA and plasma viral RNA with neurological disease status was calculated for the $40 \mathrm{HIV(+)}$ individuals in this study. Neurological disease ranged from normal to mild (stage 1) and was dichotomously classified as normal or minimal-mild (stages $0.51-1$ ). The additive effects of CSF virus or plasma virus with CSF toxicity were correlated with neurological disease status to evaluate the possible independent contribution of viremia and toxin accumulation to disease progression. The combined influence of CSF virus and high toxicity resulted in the highest correlation.
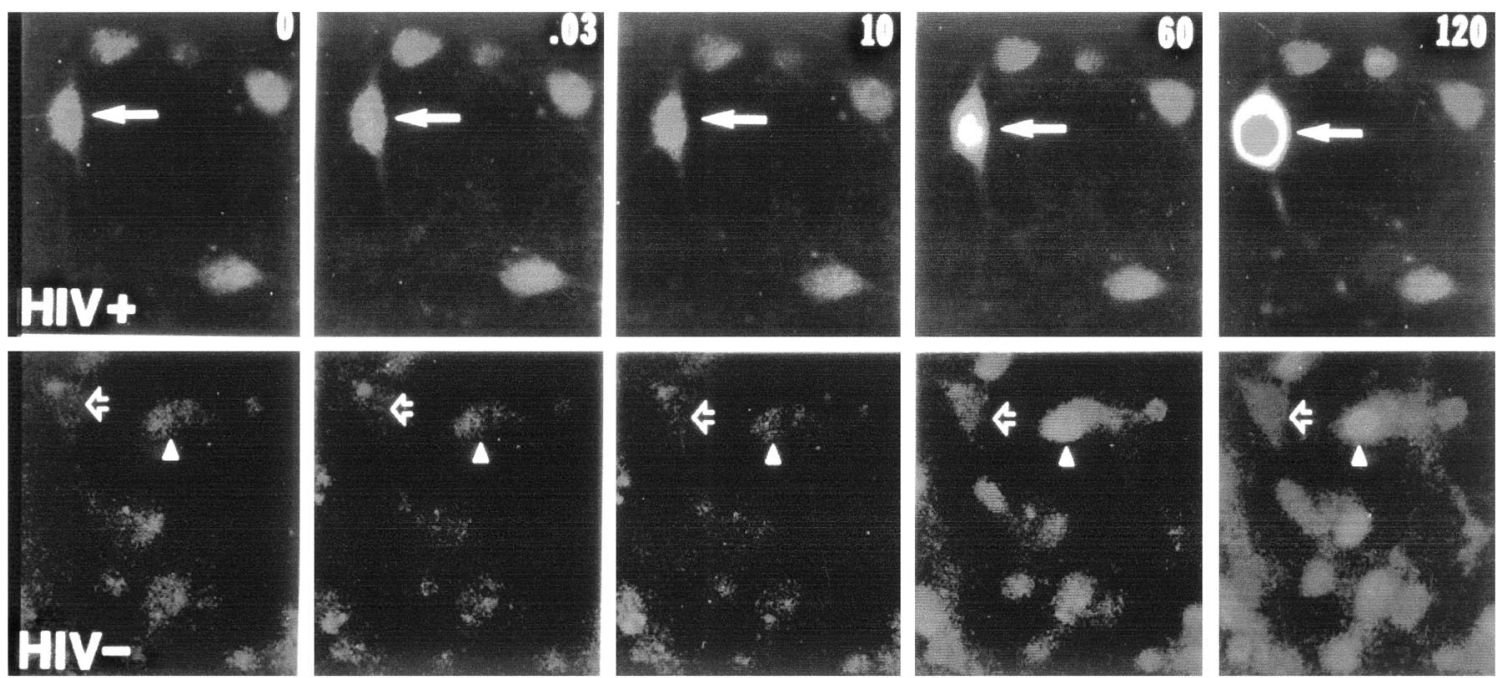

Figure 8 Example of the individual neuronal responses to toxic CSF illustrating the selective vulnerability of some neurons. Frames illustrate cell fluorescence prior to CSF application $(0 \mathrm{~min})$ and $0.03,10,60$ and $120 \mathrm{~min}$ after application. One large cortical neuron (arrow) showed a very small acute increase at 0.03 min followed by a dramatic accumulation of calcium and swelling by 120 min. Other cells in the same field showed small or negligible increases in calcium. Large cortical neurons treated with HIV $(-)$ CSF showed small increases in calcium (open arrow, arrowhead) after 60 and $120 \mathrm{~min}$ but rarely reached levels seen in responsive neurons treated with HIV(+) CSF. All CSF samples were tested on punch-cultured cortical neurons at a dilution of 1:20 in a HEPES buffered artificial CSF solution. 


\section{Discussion}

Most evidence indicates that severe neurological disease is the result of interactions of HIV with microglia and astrocytes in the brain that lead to the secretion of a number of possible neurotoxic factors (Epstein et al, 1997). Early infiltration of macrophages (Lane et al, 1996) and interactions of the virus with microglia and astrocytes may initiate a persistent inflammatory cascade with release of putative neurotoxins. Since this process evolves gradually, early markers of the neurotoxic cascade could provide important insights into the evolution of CNS disease. In addition, information regarding the identity and expression of potential toxins at various disease stages could help to clarify the nature of long-term interactions of virus within the brain. The current studies addressed two main issues: (1) Can toxic activity be detected in HIV(+) CSF prior to the development of neurological disease?; and (2) How do in vivo toxic factors affect neurons? The ultimate goal of these studies, using longitudinal analyses, will be to identify the relationship between toxic factors in CSF and clinical disease progression.

\section{A subset of HIV(+) CSF samples is neurotoxic in vitro}

The data show that CSF from HIV-infected humans can contain factors that are toxic to neurons in vitro. The toxic factors are active in rat cortical cultures providing a convenient and reliable detection system. Based on this assay, $32.5 \%$ of the $\mathrm{HIV}(+)$ CSF samples was found to have toxic activity significantly greater than $\mathrm{HIV}(-)$ CSF controls. The toxic activity was present in CSF from asymptomatic, symptomatic and AIDS patients reinforcing the view that such factors appear throughout the course of CNS disease. The level of toxicity is relatively low, as should be expected, representing a loss of approximately $2.5 \%$ of the cultured neurons. This mimics the level of neuronal loss seen in vivo and suggests similar potencies in vivo and in vitro. The factor(s) present in the CSF of $\mathrm{HIV}(+)$ patients have a relatively low molecular weight $(<30 \mathrm{kDa})$, are relatively stable and induce a gradual accumulation of intracellular $\mathrm{Ca}^{2+}$ with little acute excitotoxic actions. Thus a number of putative large or unstable toxic factors including viral envelope proteins (Lipton et al, 1991; Brenneman et al, 1988; Nath and Geiger, 1998) and nitric oxide (Dawson et al, 1993; Adamson et al, 1996) are unlikely to be the active factors in the CSF. In addition, the actions on neurons do not support the presence of direct excitotoxins such as glutamate and quinolinate (Heyes et al, 1991a,b). The absence of these factors in the CSF however, does not negate their potential contribution to toxicity in brain parenchyma. Indeed, it is likely that a variety of factors may contribute to the development of disease. Interactions of virus or viral proteins with cellular targets and generation of nitric oxide may precede the release of more stable toxins or may represent independent steps in the chain of events leading to neurotoxicity. Combined interactions of virus exposure with toxin accumulation are supported by the substantial improvement in the correlation with early clinical disease status when the additive effects of CSF toxins and viral burden were evaluated.

Previous assays for specific substances in brain and CSF have provided a list of potential neurotoxins that could contribute to our current results. The most prominent candidates include TNF- $\alpha$ (Grimaldi et al, 1991; Nuovo and Alfieri, 1996; Wesselingh et al, 1997), IL-6 (Sopper et al, 1996), PAF (Gelbard et al, 1994a) and NTox (Giulian et al, 1996). Each of these cytokines/toxins have been shown to promote neurotoxicity in vitro (Westmoreland et al, 1996; Yeung et al, 1995; Holliday et al, 1995; Giulian et al, 1996). In addition, a number of viral proteins other than gp120 could contribute to toxicity. The small regulatory protein, Tat, has been shown to be toxic to neurons (Magnuson et al, 1995; New et al, 1997) and may be secreted from infected cells (Ensoli et al, 1993). In addition, the viral proteins Nef and Rev are abundantly synthesized in astrocytes, particularly within the brains of patients with AIDS dementia (Ranki et al, 1995). However, the role of these latter proteins in the pathogenesis of AIDS dementia has been questioned (McPhee et al, 1998). Future longitudinal analyses of toxic CSF and pharmacological characterization studies should help to clarify the potential role of these substances in vivo during disease progression.

\section{$H I V(+)$ CSF induces a gradual increase in} intracellular $\mathrm{Ca}^{2+}$ in selected neurons

Neurons that are sensitive to the toxic effects of $\mathrm{HIV}(+)$ CSF exhibit a unique pattern of $\mathrm{Ca}^{2+}$ accumulation. After exposure to the CSF, a slow increase in intracellular $\mathrm{Ca}^{2+}$ develops over a period of approximately $1 \mathrm{~h}$ and in the absence of any significant acute $\mathrm{Ca}^{2+}$ influx. This response is similar to the late phase of $\mathrm{Ca}^{2+}$ accumulation described by Tymianski et al (1993) following NMDA receptor stimulation and the delayed $\mathrm{Ca}^{2+}$ increase observed in ciliary ganglion neurons exposed to feline leukemia virus envelope protein (Mitchell et al, 1997). In the studies of Tymianski et al (1993), the magnitude of the late $\mathrm{Ca}^{2+}$ accumulation predicted which cells would die. The slow accumulation followed the acute NMDA response but was independent of NMDA receptor activity and extracellular $\mathrm{Ca}^{2+}$. The late increase was attributed to a breakdown in intracellular $\mathrm{Ca}^{2+}$ homeostasis, although the precise mechanism was not determined. Although several putative toxins appear to require NMDA receptor activation (Gelbard et al, 1994b; Lipton, 1992b; Dawson et al, 1993; 
Giulian et al, 1996; New et al, 1997), the mechanisms underlying the long-term destabilization of intracellular $\mathrm{Ca}^{2+}$ are not clear. A role for intracellular release of $\mathrm{Ca}^{2+}$ has been suggested in some studies showing that dantrolene, an antagonist of ryanodine receptor mediated $\mathrm{Ca}^{2+}$ release, can partially block the toxic effects of nitric oxide (Dawson et al, 1993) or HIV gp120 envelope protein (Nath et al, 1995). We have seen similar $\mathrm{Ca}^{2+}$ responses when neural tissue is exposed to infectious virions of feline immunodeficiency virus (unpublished results) suggesting the release of similar toxic factors. Thus, the response of neural cells to virus in vitro may give rise to the release of toxins similar to those that appear in CSF in vivo.

It is important to note that only a fraction of the cultured cells die or respond with robust $\mathrm{Ca}^{2+}$ accumulation (e.g. Figure 8) after exposure to the CSF toxins. This selective cellular vulnerability is similar to that described for exposure of neural cultures to HIV envelope protein (Nath and Geiger, 1998) or to free virus in the feline immunodeficiency virus model (Meeker et al, 1996) and may reflect the processes that lead to selective neuronal loss in vivo (Wiley et al, 1991; Everall et al, 1991; Gray et al, 1991; Meeker et al, 1997). Thus, this model may provide the opportunity to more precisely define the interactions that determine which neurons will die.

\section{Clinical correlates of HIV(+) CSF toxicity}

Establishing a relationship between toxic activity in CSF and disease is the most difficult aspect of these experiments and can be only partially addressed in the context of these studies due to high variability, the current lack of longitudinal analyses and a limited number of Tox(+) samples. Future longitudinal studies are particularly important because the temporal relationship between viremia, toxin accumulation and neurological disease is currently unknown. In the current studies only a single time point has been examined for each patient and therefore trends must be viewed cautiously. Over time, many factors may contribute to CNS disease progression. For this reason it is particularly important to follow the Tox(+) asymptomatic individuals to determine if they will develop neurological disease.

Previous studies of CSF viral RNA burden have shown significant correlations with neurological disease (Robertson et al, 1998; McArthur et al, 1997; Brew et al, 1997). However, these correlations are restricted to AIDS patients with neurological disease or encephalitis and show little predictive value early in the course of disease. Our results on this small set of patients indicate that additive models that take into account both the presence of virus and the accumulation of putative toxins in the CSF may have useful predictive validity. Thus, assays for toxicity in the CSF of HIV-infected patients could provide indices of neurological disease progression and lead to valuable insights into CNS pathogenesis.

\section{Materials and methods}

Preparation of CSF samples

CSF was centrifuged at 2500 r.p.m. for $15 \mathrm{~min}$ aliquoted and frozen at $-80^{\circ} \mathrm{C}$. Prior to use in the experiments, the CSF was thawed, and half of the aliquot ( $\sim 500 \mu \mathrm{l}$ ) centrifuged through an ultrafiltration membrane with a 30000 dalton cutoff. The ultrafiltrate and the remaining raw CSF was then frozen on dry ice in $100 \mu \mathrm{l}$ aliquots and stored at $-80^{\circ} \mathrm{C}$.

\section{Primary cultures of rat cortex}

Fetuses at E17-18 were removed from pregnant female Long-Evans rats terminally anesthetized with isoflurane. The fetuses were removed from the uterus and were placed in ice cold HEPESbuffered Hank's balanced salt solution (HBSS). The brain was removed from the cranium within a laminar flow hood and rinsed three times in fresh sterile HBSS. The dura-arachnoid membrane was removed and the brains processed for punch cultures or dissociated cultures.

Cortical punch cultures These, used for calcium imaging, were taken from frontal-parietal cortex using a 23 ga blunt-tip needle connected to a $1 \mathrm{ml}$ syringe filled with sterile Dulbecco's Modified Eagle Medium (DMEM) $+10 \%$ fetal bovine serum (FBS) $+20 \mu \mathrm{g} / \mathrm{ml}$ gentamycin (complete medium). The punched pieces of tissue extracted with mild suction were then gently ejected onto poly-L-lysine $(0.1 \mathrm{mg} / \mathrm{ml})$ treated glass coverslips and transferred directly to a $5 \% \mathrm{CO}_{2}$ incubator at $35-36^{\circ} \mathrm{C}$ with just enough medium to keep them wet. The tissue punches generally attached within $2 \mathrm{~h}$ and were supplemented with additional medium approximately $2-4 \mathrm{~h}$ after plating. After $6-8$ days in vitro, cortical neurons have migrated into the region surrounding the punch. These neurons have morphological features typical of mature cortical neurons and were easily identified for imaging studies. Cells were fed with complete medium every 2 days.

Dissociated cultures These were prepared from the remaining cortical tissue. Pieces of cortex were transferred to calcium-magnesium-free HBSS (CMF-HBSS), minced and incubated in 5-10 ml of CMF-HBSS containing 2 units/ml Dispase and 2.5 units $/ \mathrm{ml}$ DNase for $10-15 \mathrm{~min}$ at $37^{\circ} \mathrm{C}$. The 
tissue was then gently triturated using 5-6 passes through a sterile $10 \mathrm{ml}$ pipette. The pieces were allowed to settle for $2 \mathrm{~min}$ and the suspended cells were transferred to a $50 \mathrm{ml}$ culture tube containing $20 \mathrm{ml}$ of complete medium. The remaining tissue was re-suspended in $5 \mathrm{ml}$ of CMF-HBSS and the trituration procedure repeated. After approximately $6-8$ cycles of trituration the final tube of cells was centrifuged at 400 r.p.m. for $10 \mathrm{~min}$ to collect the cells as a loose 'pellet'. The supernatant was checked for residual cells and then aspirated. The cells were resuspended in complete medium at a concentration of approximately 500000 cells $/ \mathrm{ml}$. The cells were then seeded into 48-well plates at a density of approximately 100000 cells $/ \mathrm{cm}^{2}$. The resulting cultures contained a mixed population of neurons, glia and microglia.

\section{Evaluation of CSF cytotoxicity}

Dissociated cultures seeded at identical densities in multiwell plates were used for cytotoxicity analysis to provide optimal uniformity between cultures. Cultures were screened prior to use to remove those with poor growth, non-uniformity or other problems. Evaluation of CSF effects on the cultured neurons was accomplished by washing the cultures twice in HBSS followed by addition of $250 \mu \mathrm{l} /$ well of serum-free DMEM containing CSF at concentrations ranging from $1: 5$ to $1: 1000$ with each condition run in triplicate. Controls included a minimum of 9 wells/plate receiving an equal volume of artificial CSF (aCSF in mM; $\mathrm{NaCl} 130$, $\mathrm{KCl} 5.0, \mathrm{CaCl}_{2}$ 2.3, $\mathrm{MgCl}_{2}$ 1.3, $\mathrm{NaHCO}_{3}$ 24, glucose 10) as well as CSF samples obtained from HIVnegative $[\mathrm{HIV}(-)]$ individuals. $\mathrm{HIV}(-)$ CSF was collected from patients receiving CT-myelograms with no known underlying neurological disease. The cells were incubated for $18-28 \mathrm{~h}$ under standard culture conditions $\left(37^{\circ} \mathrm{C}, 5 \% \mathrm{CO}_{2}\right)$. At the end of the incubation, $100 \mu \mathrm{l}$ of medium was collected from each well for the subsequent assay of lactate dehydrogenase (LDH) activity. The cells were then washed twice in HBSS and incubated in a $2 \mu \mathrm{M}$ solution of ethidium homodimer in DMEM under standard culture conditions for a period of $30 \min \left(37^{\circ} \mathrm{C}\right.$ in a $5 \% \mathrm{CO}_{2}$ humidified incubator). After three washes in HBSS to remove excess stain, the fluorescent red nuclei of dead cells were systematically imaged and counted in triplicate fields from each culture at a final magnification of $106 \times$. The red fluorescent nuclei provide a very high signal to noise with virtually no background. The digital image of the fluorescent nuclei was highlighted and the size of each nucleus measured automatically using a Bioquant Image Analysis System (R \& M Biometrics). Each highlighted object was then filtered based on size $\left(\mu \mathrm{m}^{2}\right)$ and objects counted which fell in the range of cell nuclei (calibrated from stained cells cultured under the same conditions). The mean number of dead cells was calculated for each well and corrected for basal cell death measured in wells treated with aCSF. The per cent increase (or decrease) in cell death relative to basal was then calculated and a 95\% confidence limit calculated from the cell death observed in cultures treated with $\mathrm{HIV}(-)$ CSF. This limit was then used to determine which HIV(+) CSF samples had significant cytotoxic activity.

Assay for lactate dehydrogenase activity in the tissue culture medium was accomplished using the Optimized LDH Assay kit (Sigma Chemical Co.). Each CSF sample was analyzed in triplicate according to the following modified protocol. Reagent A (NADH and phosphate buffer, pH 7.5) was added in a volume of $1.25 \mathrm{mls}$ to a tube containing $100 \mu \mathrm{l}$ of culture medium, the tube was gently mixed and allowed to react for $1 \mathrm{~min}$. Reagent B (pyruvate solution) was added in a volume of $50 \mu \mathrm{l}$, the solutions mixed and incubated for $30 \mathrm{~s}$. The conversion of pyruvate to lactate by LDH with the corresponding oxidation of NADH to $\mathrm{NAD}^{+}$was measured by the decrease in absorbance at $340 \mathrm{~nm}$ at $1 \mathrm{~min}$ intervals over a total period of $3 \mathrm{~min}$. The rate of decrease (absorbance units/min) is proportional to the $\mathrm{LDH}$ activity $(\mathrm{U} / \mathrm{ml})$ in the sample. The assay was found to be linear for at least 4 min.

Correlation of the results obtained from the ethidium homodimer versus LDH for assays run at the same time generally yielded good concordance but correlations were modest. The largest direct comparison between cell death and LDH for an assay in which 42 samples were run in parallel gave a correlation of 0.658 .

\section{Assessment of apoptotic cell death}

After quantification of cell death based on the ethidium homodimer stain, selected cultures were fixed for $10 \mathrm{~min}$ in $4 \%$ paraformaldehyde, $0.1 \mathrm{M}$ phosphate buffer, pH 7.4. Deoxynucleotidyl terminal transferase end labeling of DNA fragments was accomplished using the TdT FragEL kit (Amersham Corp.). The cells were rinsed in $0.05 \mathrm{M}$ Trisbuffered Saline (TBS), $3 \times 5 \mathrm{~min}$ and treated for $5 \mathrm{~min}$ at room temperature with $2 \mu \mathrm{g} / \mathrm{ml}$ proteinase $\mathrm{K}$ in $10 \mathrm{mM}$ Tris buffer, $\mathrm{pH}$ 8.0. The cells were again rinsed $3 \times 5 \mathrm{~min}$ in TBS and then incubated in $0.6 \% \mathrm{H}_{2} \mathrm{O}_{2}$ for $15 \mathrm{~min}$. After rinsing $3 \times 5 \mathrm{~min}$ in TBS, TdT buffer was added to the cells and allowed to stand for $30 \mathrm{~min}$. TdT labeling reaction mix and TdT enzyme, premixed on ice, were then added to the cells and incubated at $37^{\circ} \mathrm{C}$ for $1.5 \mathrm{~h}$. The reaction was stopped, the cells washed and avidin-HRP added in blocking solution. Cells were reacted with diaminobenzidine, washed and counterstained with methyl green. The density of stained 
nuclei was evaluated and compared with results from the ethidium homodimer stain. Positive controls in which the cultures were treated with DNase yielded robust, widespread staining.

Digital morphometry and calcium imaging After a minimum of 8 days in vitro, coverslips containing cortical punches were washed twice in HEPES-buffered artificial CSF (HEPES-aCSF) composed of the following salts (mM concentration): $\mathrm{NaCl}$ 137, $\mathrm{KCl}$ 5.0, $\mathrm{CaCl}_{2}$ 2.3, $\mathrm{MgCl}_{2}$ 1.3, HEPES 10, glucose $20 ; \mathrm{pH}=7.36-7.40$, osmolality $=290 \mathrm{mOsm} /$ $\mathrm{kg}$. After the second wash, a $4 \mu \mathrm{M}$ solution of the fluorescent $\mathrm{Ca}^{2+}$ indicator, Fluo-3 AM (Molecular Probes, Inc.), dissolved in HEPES-aCSF was added and the cells were allowed to incubate for $40 \mathrm{~min}$ in a humidified chamber at room temperature. The working Fluo-3 AM solution was made by diluting from a $2 \mathrm{mM}$ stock in DMSO. After incubation in the Fluo-3 AM, cells were washed three times with HEPES-aCSF and the coverslip was transferred to Biophysica chamber for the imaging studies. A volume of $0.5 \mathrm{ml}$ of HEPES-aCSF was placed on

\section{References}

Adamson DC, Wildemann B, Sasaki M, Glass JD, MacArthur JC, Christov VI, Dawson TM, Dawson VL (1996). Immunologic NO synthetase: elevation in severe AIDS dementia and induction by HIV-1 gp41. Science 274: 1917-1921.

Bossi P, Dupin N, Coutellier A Bricaire F, Lubetzki C, Katlama C, Calvez V (1998). The level of human immunodeficiency virus (HIV) type 1 RNA in cerebrospinal fluid as a marker of HIV encephalitis. Clin Infect Dis 26: 1072-1073.

Brenneman D, Westbrook G, Fitgerald S, Ennis D, Elkins K, Ruff M, Pert C (1988). Neuronal cell killing by the envelope protein of HIV and its prevention by vasoactive intestinal peptide. Nature 335: 639-642.

Brew BJ, Pemberton L, Cunningham P, Law MG (1997). Levels of human immunodeficiency virus type 1 RNA in cerebrospinal fluid correlate with AIDS dementia stage. J Infect Dis 175: $963-966$.

Conrad AJ, Schmid P, Syndulko K, Singer EJ, Nagra RM, Russell JJ, Tourtellotte WW (1995). Quantifying HIV-1 RNA using the polymerase chain reaction on cerebrospinal fluid and serum of seropositive individuals with and without neurologic abnormalities. J Acquir Immune Defic Syndr Hum Retrovir 10: 425-435.

Dawson V, Dawson T, Uhl G, Synder S (1993). Human immunodeficiency virus type 1 coat protein neurotoxicity mediated by nitric oxide in primary cortical cultures. Proc Natl Acad Sci USA 90: 3256-3259.

Dreyer K, Kaiser P, Offerman J, Lipton S (1990). HIV-1 coat protein neurotoxicity prevented by calcium channel antagonists. Science 248: 364-367. the coverslip. After triplicate measurements of basal $\mathrm{Ca}^{2+}$ in the cells, an additional $0.5 \mathrm{ml}$ aliquot of HEPES-aCSF containing a $1: 10$ dilution of human CSF was applied to the culture (final dilution of $1: 20$ ). Images were collected over a period of $2 \mathrm{~h}$ after addition of the CSF.

A Bioquant Meg M Image Analysis System coupled to an Olympus IMT-2 microscope was used for the $\mathrm{Ca}^{2+}$ measurements. For most analyses, cells were imaged at a final magnification of $1634 \times$. Regions were selected to contain large cortical neurons. If possible, smaller neurons and microglia, were included for comparison. Images of the cell and basal fluorescence were collected using an MTI camera coupled to a Genesis II image intensifier. The mean of three pre-stimulation measurements \pm s.d. was used to define the range of values considered to be basal $\mathrm{Ca}^{2+}$ fluorescence. The proportional increase in fluorescence intensity within each cell was then measured relative to the average of the baseline measurements to correct for cell to cell differences in dye loading and intrinsic fluorescence $\left(\Delta \mathrm{F} / \mathrm{F}_{\text {baseline }}\right)$.

Ellis RJ, Hsia K, Spector SA, Nelson JA, Heaton RK, Wallace MR, Abramson I, Atkinson JH, Grant I, McCutchan JA (1997). Cerebrospinal fluid human immunodeficiency virus type 1 RNA levels are elevated in neurocognitively impaired individuals with acquired immunodeficiency syndrome. HIV Neurobehavioral Research Center Group. Ann Neurol 42: $679-688$.

Elovaara I, Poutianien E, Raininko R, Valanne L, Virta A, Valle S, Lahdevirta J, Iivanainen M (1990). Mild brain atrophy in early HIV infection: the lack of association with cognitive deficits and HIV-specific intrathecal immune response. J Neurol Sci 99: 121-136.

Ensoli B, Buonaguro L, Barillari G, Fiorelli V, Gendelman R, Morgan RA, Wingfield P, Gallo RC (1993). Release, uptake and effects of extracellular human immunodeficiency virus type 1 Tat protein on cell growth and viral transactivation. J Virol 67: 277-287.

Epstein L, Gendelman H, Lipton S (1997). Human immunodeficiency virus-1 neuropathogenesis. In: AIDS and the Nervous System. Berger JR Levy RM (eds), pp 59-75. Philadelphia: Lippincott-Raven.

Everall I, Luthert P, Lantos P (1991). Neuronal loss in the frontal cortex in HIV infection. Lancet 337: 11191121.

Gelbard HA, Nottet HS, Swindells S, Jett M, Dzenko KA, Genis P, White R, Wang L, Choi YB, Zhang D, Lipton, SA, Tourtellotte WW, Epstein LG, Gendelman HE (1994a). Platelet-activating factor: a candidate human immunodeficiency virus type 1-induced neurotoxin. $J$ Virol 68: $4628-4635$. 
Gelbard HA, Dzenko K, Diloreto D, Delcerro C, Epstein LG (1994b). Neurotoxic effects of tumor necrosis factor in primary human neuronal cultures are mediated by activation of the glutamate AMPA receptor subtype: implications for AIDS neuropathogenesis. Dev Neurosci 15: $418-422$.

Giulian D, Yu J, Li X, Tom D, Li J, Wendt E, Lin S-N, Schwarcz R, Noonan C (1996). Study of receptormediated neurotoxins released by HIV-1-infected mononuclear phagocytes found in human brain. $J$ Neurosci 16: 3139-3153.

Glass JD, Fedor H, Wesselingh SL, McArthur JC (1995). Immunocytochemical quantitation of human immunodeficiency virus in the brain: correlations with dementia. Ann Neurol 38: 755-762.

Gray F, Haug H, Chimelli L, Geny C, Gaston A, Scaravilli F, Budka H (1991). Prominent cortical atrophy with neuronal loss as correlate of human immunodeficiency virus encephalopathy. Acta Neuropathol (Berl) 82: $229-233$.

Grimaldi LM, Martino GV, Franciotta DM, Brustia R, Castagna A, Pristera R, Lazzarin A (1991). Elevated alpha-tumor necrosis factor levels in spinal fluid from HIV-1 infected patients with central nervous system involvement. Ann Neurol 29: 21-25.

Heyes MP, Brew B, Martin A, Markey SP, Price RW, Bhalla RB, Salazar A (1991a). Cerebrospinal fluid quinolinic acid concentrations are increased in acquired immune deficiency syndrome. Adv Exp Med Biol 294: 687-690.

Heyes MP, Brew BJ, Martin A, Price RW, Salazar AM, Sidtis JJ, Yergey JA, Mouradian MM, Sadler AE, Kelip J, Rubinow D, Markey SP (1991b). Quinolinic acid in cerebrospinal fluid and serum in HIV-1 infection: relationship to clinical and neurological status. Ann Neurol 29: 202-209.

Holliday J, Parsons K, Curry J, Lee SY, Gruol DL (1995). Cerebellar granule neurons develop elevated calcium responses when treated with interleukin-6 in culture. Brain Res 673: $141-148$.

Ketzler S, Weis S, Haug H, Budka H (1990). Loss of neurons in the frontal cortex in AIDS brains. Acta Neuropathol 80: $92-94$.

Lane JH, Sasseville VG, Smith MO, Vogel P, Pauley DR, Heyes MP, Lackner AA (1996). Neuroinvasion by simian immunodeficiency virus coincides with increased numbers of perivascular macrophages/microglia and intrathecal immune activation. J NeuroVirol 2: $423-432$.

Lendhardt T, Super M, Wiley C (1988). Neuropathological changes in an asymptomatic HIV seropositive man. Ann Neurol 23: 209-210.

Lipton S, Sucher N, Kaiser P, Dreyer E (1991). Synergistic effects of HIV coat protein and NMDA receptor-mediated neurotoxicity. Neuron 7: 111-118.

Lipton S (1992a). Requirement of macrophages in neuronal injury induced by HIV envelope protein gp120. NeuroReport 3: 913-915.

Lipton S (1992b). Models of neuronal injury in AIDS: another role for the NMDA receptor? TINS 15: 75-80.

Magnuson D, Knudsen B, Geiger J, Brownstone R, Nath A (1995). Human immunodeficiency virus type 1 Tat activates non-M-methyl-D-aspartate excitatory amino acid receptors and causes neurotoxicity. Ann Neurol 37: $373-380$.
McArthur JC, McClernon DR, Cronin MF, Nance-Sproson TE, Saah AJ, St Clair M, Lanier ER (1997). Relationship between human immunodeficiency virus-associated dementia and viral load in cerebrospinal fluid and brain. Ann Neurol 42: 689-698.

McPhee DA, Greenway AL, Holloway G, Smith K, Deacon N, Pemberton L, Brew BJ (1998). Anomalies in Nef expression within the central nervous system of HIV-1 positive individuals/AIDS patients with or without AIDS dementia complex. J Neurovirol 4: $291-300$.

Meeker RB, English R, Tompkins M (1996). Enhanced excitotoxicity in primary feline neural cultures exposed to feline immunodeficiency virus (FIV). J NeuroAIDS 1: 1-27.

Meeker RB, Thiede BA, Hall C, English R, Tompkins M (1997). Cortical cell loss in asymptomatic cats experimentally infected with feline immunodeficiency virus. AIDS Res Hum Retrovir 13: 1131-1140.

Mitchell TW, Rojko JL, Hartke JR, Mihajlov AR, Kasameyer GA, Gasper PW, Whalen LR (1997). FeLV envelope protein (gp 70) variable region 5 causes alterations in calcium homeostasis and toxicity of neurons. J Acquir Immune Defic Syndr Hum Retrovirol 14: $307-320$.

Nath A, Padua RA, Geiger JD (1995). HIV-1 coat protein gp120-induced increases in levels of intrasynaptosomal calcium. Brain Res 678: 200-206.

Nath A, Geiger JD (1998). Neurobiological aspects of human immunodeficiency virus infection: neurotoxic mechanisms. Prog Neurobiol 54: 19-33.

New DR, Ma M, Epstein LG, Nath A, Gelbard HA (1997). Human immunodeficiency virus type 1 Tat protein induces death by apoptosis in primary human neuron cultures. J Neurovirol 3: 168-173.

Nuovo GJ, Alfieri ML (1996). AIDS dementia is associated with massive, activated HIV-1 infection and concomitant expression of several cytokines. Mol Med 2: $358-366$.

Price RW, Sidtis JJ (1990). Evaluation of the AIDS Dementia Complex in clinical trials. J AIDS 3(S2): S51-S60.

Ranki A, Nyberg M, Ovod V, Haltia M, Elovaara I, Raininko R, Haapasalo H, Krohn K (1995). Abundant expression of HIV Nef and Rev proteins in brain astrocytes in vivo is associated with dementia. AIDS 9: $1001-1008$.

Robertson K, Fiscus S, Kapoor C, Robertson W, Schneider G, Shepard R, Howe L, Silva S, Hall C (1998). CSF, plasma viral load and HIV associated dementia. J Neurovirol 4: 90-94.

Sopper S, Demuth M, Stahl-Hennig C, Hunsmann G, Plesker R, Coulibaly C, Czub S, Ceska M, Koutsilieri E, Riederer P, Brinkmann R, Katz M, ter Meulen V (1996). The effect of simian immunodeficiency virus infection in vitro and in vivo on the cytokine production of isolated microglia and peripheral macrophages from rhesus monkey. Virology 220: $320-329$

Tymianski M, Charlton MP, Carlen PL, Tator CH (1993). Source specificity of early calcium neurotoxicity in cultured embryonic spinal neurons. J Neurosci 13: $2085-2104$ 
Weis S, Haug H, Budka H (1993). Neuronal damage in the cerebral cortex of AIDS brains: a morphometric study. Acta Neuropathol (Berl) 85: 185-189.

Wesselingh SL, Takahashi K, Glass JD, McArthur JC, Griffin JW, Griffin DE (1997). Cellular localization of tumor necrosis factor mRNA in neurological tissue from HIV-infected patients by combined reverse transcriptase/polymerase chain reaction in situ hybridization and immunohistochemistry. J Neuroimmunol 74: $1-8$.

Westmoreland SV, Kolson D, Gonzalez-Scarano F (1996). Toxicity of TNF alpha and platelet activating factor for human NT2N neurons: a tissue culture model for human immunodeficiency virus dementia. J Neurovirol 2: $118-126$.
Wiley C, Masliah E, Morey M, Lemere C, DeTeresa R, Grafe M, Hansen L, Terry R (1991). Neocortical damage during HIV infection. Ann Neurol 29: 651657.

Yeung MC, Pulliam L, Lau AS (1995). The HIV envelope protein gp120 is toxic to human brain-cell cultures through the induction of interleukin-6 and tumor necrosis factor-alpha. AIDS 9: 137-143. 